\title{
El conocimiento didáctico del contenido en química: integración de las tramas de contenido histórico-epistemológicas con las tramas de contexto-aprendizaje
}

\author{
William Manuel Mora Penagos ${ }^{2}$ \\ Diana Lineth Parga Lozano ${ }^{3}$
}

Artículo recibido: 30- 09-2008 y aprobado: 27-11-2008.

Didactic knowledge of content in chemistry: integration of the content scope with historical and epistemological scope and context-learning scope

Resumen: Este artículo es una continuidad de trabajos anteriores relacionados con la necesidad de profesionalizar el diseño curricular en química (Mora y Parga, 2005), la construcción de tramas histórico-epistemológicas por niveles evolutivos (Mora y Parga, 2007) y la necesidad de construir un modelo investigativo sobre la formación permanente del profesorado de química (Parga, Mora y Martínez, 2007). Este documento muestra, primero, las diferencias entre la propuesta de Shulman (1986) y sus seguidores, con los planteamientos de Chevallard (1991) y el grupo DIE de la Universidad de Sevilla, acerca de los fundamentos que definen el Conocimiento Didáctico del Contenido, CDC; segundo, se propone una síntesis de la ideas fundamentales para la identificación de las Representaciones de Contenido, ReCo, y los Repertorios de Experiencia Profesional Didáctica, ReEpd, (Loughran, Berry y Mulhall, 2006) como herramientas de identificación del CDC del profesorado y de estrategias de desarrollo profesional didáctico; por último, se proponen algunos fundamentos conceptuales sobre cómo elaborar Tramas Didácticas, TD, como esenciales para el diseño de unidades didácticas de enseñanzaaprendizaje en química.

Palabras clave: Conocimiento didáctico del contenido, desarrollo profesional del profesorado de química, integración didáctica, tramas didácticas.
Abstract: This article is a continuity of previous works concerning with the needs emerging from the professionalization of Chemistry curricular design (Mora and Parga, 2005), the construction of historical and epistemological scope for evolutionary levels (Mora and Parga, 2007), and the construction of a research model focused on educational programs for pre service chemistry teachers (Parga, Mora, and Martínez, 2007). First, the authors show the differences among the proposal of Shulman (1986) and their supporters, the positions of Chevallard (1991) and positions of the IE group at Seville's University, regarding the foundations that define the Didactic Knowledge of Content, CDC. Second, they present a synthesis of fundamental ideas that will allow teachers the identification of those Representations of Content, ReCo, and those Repertoires of Didactic Professional Experience, ReEpd, (Loughran, Berry, and Mulhall, 2006) as tools for the identification of the faculty's CDC and the strategies for Professional Didactic Development. Finally, they state some conceptual foundations on how to propose the didactic scope, DS, as a basis for didactic units design regarding chemistry teaching and learning processes.

Key words: Didactic knowledge of content, chemistry teachers'professional development, didactic integration, didactic scope.

1 Este documento forma parte del marco construido en el proyecto: CIUP-DQU-025-07.

2 Profesor de planta (carrera) de la Universidad Distrital Francisco José de Caldas. Grupo DIDAQUIM. Correo electrónico:wmora@udistrital.edu.co

3 Profesora de planta del Departamento de química la Universidad Pedagógica Nacional. Grupo ALTERNACIENCIAS. Correo electrónico: dparga@pedagogica.edu.co 


\section{El Conocimiento Didáctico del Contenido, CDC, como objeto disciplinar de la práctica y desarrollo profesional del profesorado}

El Conocimiento Pedagógico del Contenido (Pedagogical Content Knowledge, pck), llamado en el escenario iberoamericano Conocimiento Didáctico del Contenido, CDC, (Mellado, 1996, Bolívar, 2005, García y Garritz, 2006), como constructo y modelo, es comúnmente aceptado en el léxico educativo actual y ha venido mostrándose con gran potencial al introducir la importancia del conocimiento del contenido en los conocimientos necesarios para la enseñanza (Gess-Newsome, 1999) y en la inclusión de estándares de desarrollo profesional de los profesores de ciencias (Garritz y Trinidad-Velasco, 2004 y Veal, 2004), pese a que sus investigaciones han sido menos cohesivas en la comunidad internacional, debido a la multiplicidad de interpretaciones que en un comienzo presentaba, si se compara con su campo afín, llamado conocimiento de la materia a enseñar, (subject matter knowledge, smk) (Abell y Lederman, 2007), y que en este artículo denominaremos como Conocimiento Disciplinar del Contenido, CDC.

En general, y como lo plantean Loughran et al. (2006), al igual que le ha sucedido al término pedagogía, el CDC puede parecer no más que una simple jerga, sin embargo, ha permitido enlazar las actuales investigaciones que examinan la relación entre la enseñanza, el aprendizaje y el contenido de enseñanza, haciendo que el CDC no solamente haya adquirido un nuevo y significativo sentido, sino que también ha abierto la práctica profesional didáctica al escruti- nio, para reconocer las habilidades y conocimientos que utilizan los profesores cuando enseñan. El CDC ha contribuido a aclarar que la enseñanza es problemática y no está entendida suficientemente, que la formación del profesorado no ha sido muchas veces más que una colección de juegos de actividades para usar en el aula, que los profesores que reflexionan en equipo para entender su enseñanza contribuyen a su desarrollo profesional didáctico y mejoran su práctica al verse reflejados en las experiencias y visiones de otros maestros y que el conocimiento profesional del profesorado requiere un lenguaje especial para facilitar la buena expresión y comprensión de las ideas sobre lo que es enseñar y aprender.

CDC no es un simple rótulo que permite igualar a todos los profesores respecto a un contenido de enseñanza dado; es más bien el producto de un conocimiento práctico que es particular, individual e idiosincrático, debido a las diferencias influenciadas por sus conocimientos, creencias, el contexto y la experiencia de enseñanza. Puede ser igual (o similar) para algunos profesores y diferente para otros, pero es una piedra angular del conocimiento y desarrollo profesional del profesorado.

El CDC ha sido promovido particularmente desde el área de enseñanza de las ciencias, destacándose la necesidad de la integración de varios dominios del conocimiento en la enseñanza, la investigación, y la preparación del profesor (Parga, Mora y Martínez, 2007).

Algunos precedentes en didáctica de las ciencias naturales son los trabajos de los profesores Gil (1991) y Furió, et al. (1992), los cuales han destacado la necesidad de conocer bien la materia a 
enseñar como conocimiento profundo de éste, enfatizando no sólo en una mejor formación en los actuales conocimientos científicos, sino también en los aspectos histórico-epistemológicos y sociales que permitieran tener mejores criterios de selección de contenidos para la enseñanza; también han destacado la necesidad de entender la formación del profesorado como un cambio didáctico del pensamiento docente de sentido común y la apropiación de una concepción teóricamente fundamentada de la enseñanza-aprendizaje de la disciplina, utilizando la investigación y la innovación en el aula. Sin embargo, estos precedentes, que son dignos de mención, no destacan explícitamente aspectos que tienen que ver con el conocimiento del contexto escolar y una clara diferenciación entre conocimiento científico, conocimiento cotidiano y conocimiento escolar, los cuales son una variable fundamental como lo mostraremos más adelante.

Desde los años ochenta, en el contexto angloamericano, Lee Shulman ha liderado la línea de investigación del PсK, que luego se ha transformado en un modelo teórico para entender la enseñanza de los contenidos, originando distintas aproximaciones en áreas generales del conocimiento escolar, como las ciencias naturales, las ciencias sociales, las artes, entre otras (Bolívar, 2005). En el medio francófono, desde los desde los años noventa, este liderazgo lo ha sumido Yves Chevallard, particularmente en la didáctica de las matemáticas. En esta época también se destacan en el medio español los trabajos del grupo de los profesores Rafael Porlán y Eduardo García-Díaz, en didáctica de las ciencias naturales y sociales. Consideramos que estos tres grupos han influido decididamente en nuestro medio el ámbito de la enseñanza y la formación del profesorado de ciencias, por lo que, sin pretender ser exhaustivos, presentamos en la Tabla 1 una síntesis de sus principales ideas y diferencias que permitan posteriormente establecer estrategias de identificación del CDC.

Mediante esta tabla es posible establecer la importancia que el CDC ha tenido en el reconocimiento de las didácticas de las disciplinas como campo disciplinar el ejercicio docente, el establecimiento de la enseñanza como profesión y la importancia que tiene la comunidad de pares docentes en la investigación e innovación sobre el diseño y la ejecución del currículo. También es posible concluir, siguiendo los trabajos de García-Díaz (1998), Porlán y Rivero (1998) y Martín del Pozo y Rivero (2001), que el CDC en general es un conocimiento de tipo práctico y profesionalizado del contenido y de su enseñanza-aprendizaje, que se contextualiza de manera disciplinar en las didácticas específicas, el cual es un conocimiento que se pretende que el profesorado construya tanto en ejercicio como en formación para que de esta manera les permita un desempeño y una intervención fundamentadas disciplinarmente, partiendo de una transformación- integración de diferentes tipos de conocimientos y saberes (académicos, creencias y principios de acción, rutinas y guiones de acción y teorías implícitas) en ocasiones desconectadas entre sí.

Por otro lado, estamos de acuerdo con la postura de García-Díaz (1998), Porlán y Rivero (1998) y Gess-Newsome (1999), en la cual el Conocimiento Didáctico del Contenido, CDC, es más un proceso de integración que de transformación o transposición (más de combinatoria 
que de mixtura, como se diría en química) en el cual los conocimientos que se integran están acompañados cada uno de creencias docentes que conforman el conocimiento base de la enseñanza, aspecto que ha sido poco tenido en cuenta por los seguidores del PCK.

Si bien, al igual que Grossman, et al. (1990), Gess-Newsome (1999), Magnusson et al. (1999) y Marcelo (2005), estamos de acuerdo con que el conocimiento del profesor (para hacer enseñables los contenidos) debe sufrir una "transformación" de cuatro distintos conocimientos (el conocimiento del contenido, el conocimiento curricular, el conocimiento pedagógico y el conocimiento del contexto).

La diferencia que asumimos es que mientras estos autores entienden el CDC como un conocimiento más, adicional al conocimiento del contenido y al conocimiento pedagógico, aquí lo asumimos no como un componente a adicionar a los ya reconocidos, sino como el producto de una "combinación de un sistema integrado" de los conocimientos (disciplinares, histórico-epistemológicos, psicopedagógicos, y contextuales -ver Figura 1-, lo cual tiene necesariamente implicaciones directas en la formación del profesorado como en el tipo de diseños curriculares que se formulen.

El modelo de transformación también sigue de cerca patrones tradicionales de la preparación del profesor al separar, temporal y espacialmente, el contenido o materia a enseñar de lo pedagógico y las referencias del contexto, dejando que sea en la práctica y el ejercicio docente cuando cada uno en forma individual y en el aislamiento no reflexionado explícitamente, intenten algún tipo de integración. Un peligro potencial en este modelo es que los profesores podrían pasar por alto la importancia de la integración del conocimiento y continuar acentuando la importancia del contenido sobre lo pedagógico, dando como resultado modos de transmisión de la enseñanza con poco respeto para la estructura epistemológica del contenido, las referencias de los procesos de aula de clase o los factores del contexto.

\section{Modelo \\ Proponentes}

\begin{tabular}{|c|c|c|}
\hline $\begin{array}{l}\text { Transformación } \\
\text { didáctica }\end{array}$ & $\begin{array}{l}\text { Transposición } \\
\text { didáctica }\end{array}$ & $\begin{array}{l}\text { Integración } \\
\text { didáctica }\end{array}$ \\
\hline $\begin{array}{l}\text { Propuesta del Modelo de } \\
\text { Traslación- Transformación } \\
\text { Pedagógica, planteado por } \\
\text { Lee Shulman (1986) y Wilson y } \\
\text { Shulman(1987) dela Universidad } \\
\text { de Stanford, Estados Unidos. }\end{array}$ & $\begin{array}{l}\text { Modelo de Trasposición Didáctica, } \\
\text { propuesta del matemático Yves } \\
\text { Chevallard (1991) de la Universidad } \\
\text { de Aix, Francia. }\end{array}$ & $\begin{array}{l}\text { Modelo de Investigación en la } \\
\text { Escuela (1991), planteado por el } \\
\text { Grupo DIE, Didáctica e Investigación } \\
\text { Escolar, de la Universidad de } \\
\text { Sevilla, España, compuesto por } \\
\text { los profesores de didáctica de las } \\
\text { ciencias experimentales y sociales } \\
\text { Rafael Porlán, Eduardo García-Díaz, } \\
\text { Francisco García-Pérez, Ana Rivero } \\
\text { y Rosa Martín del Pozo, en el marco } \\
\text { del proyecto Ires (Investigación y } \\
\text { Renovación Escolar) }\end{array}$ \\
\hline
\end{tabular}

Tabla 1: Modelos teóricos para entender la enseñanza de los contenidos. 


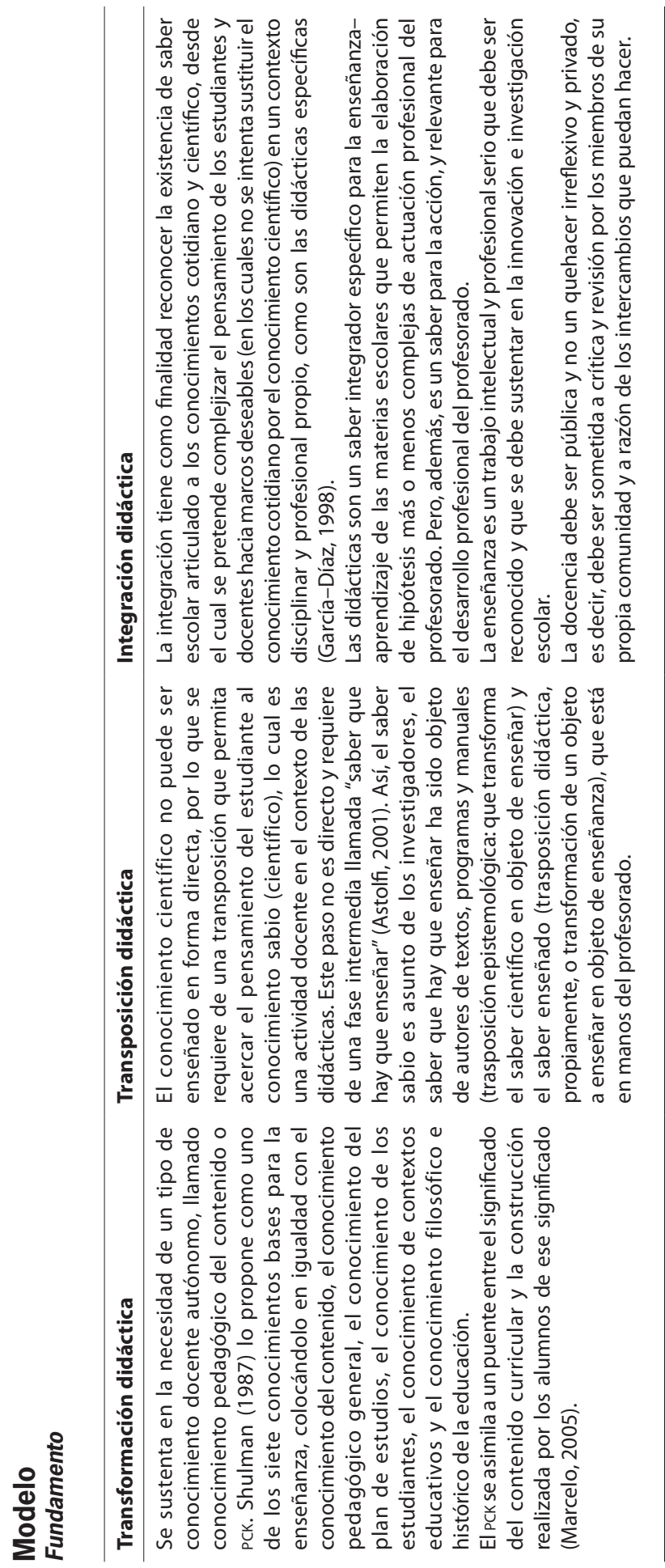




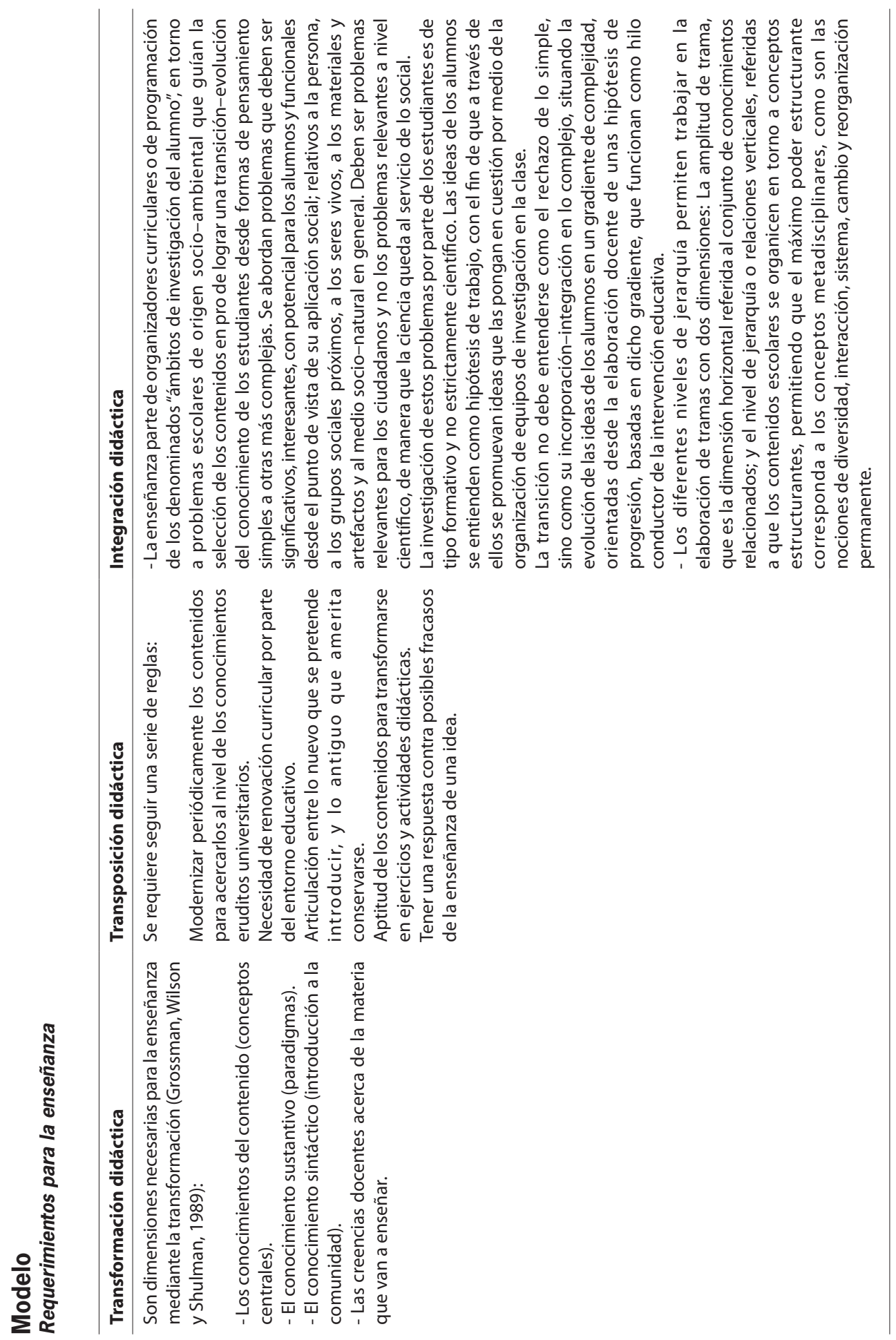




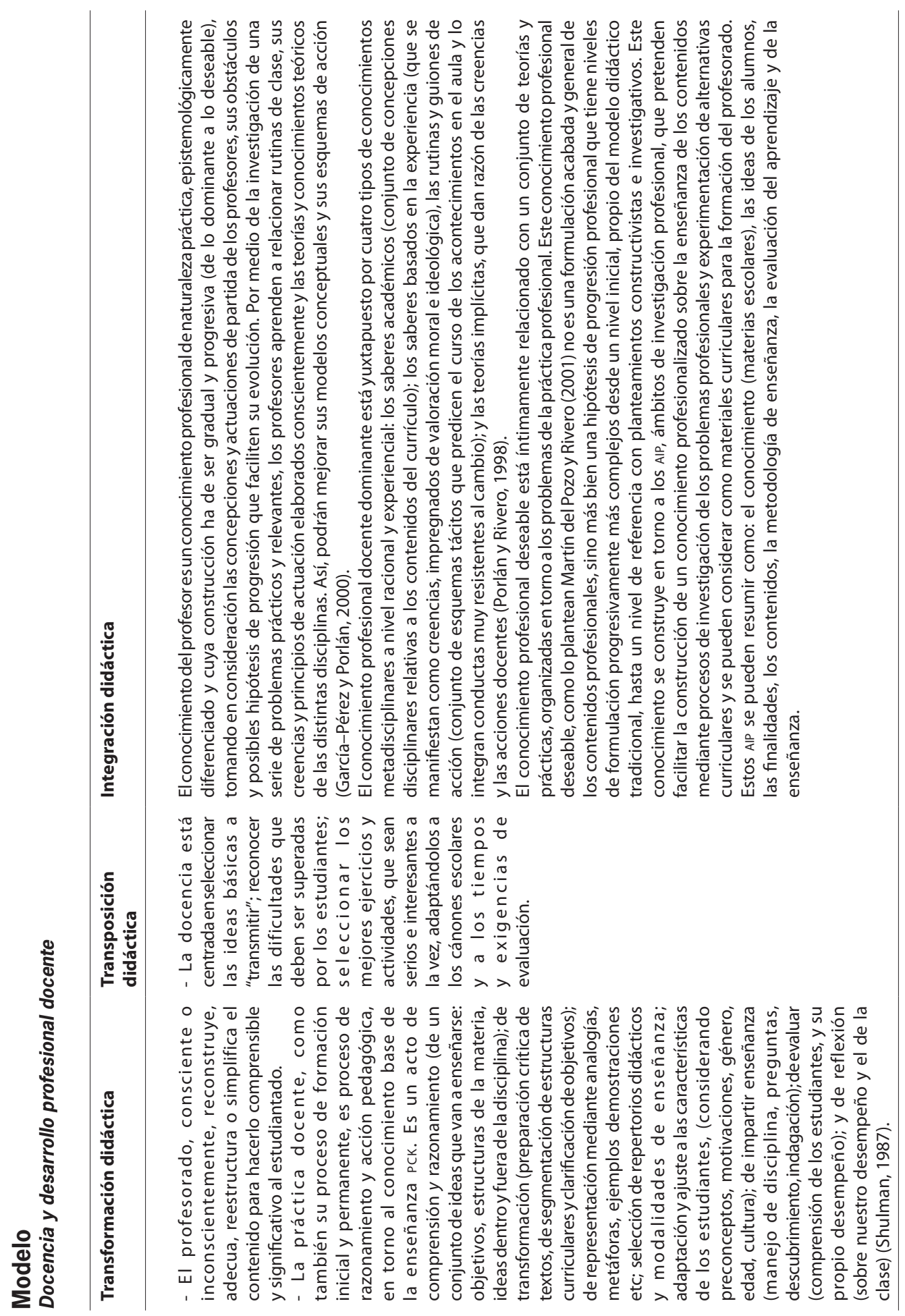




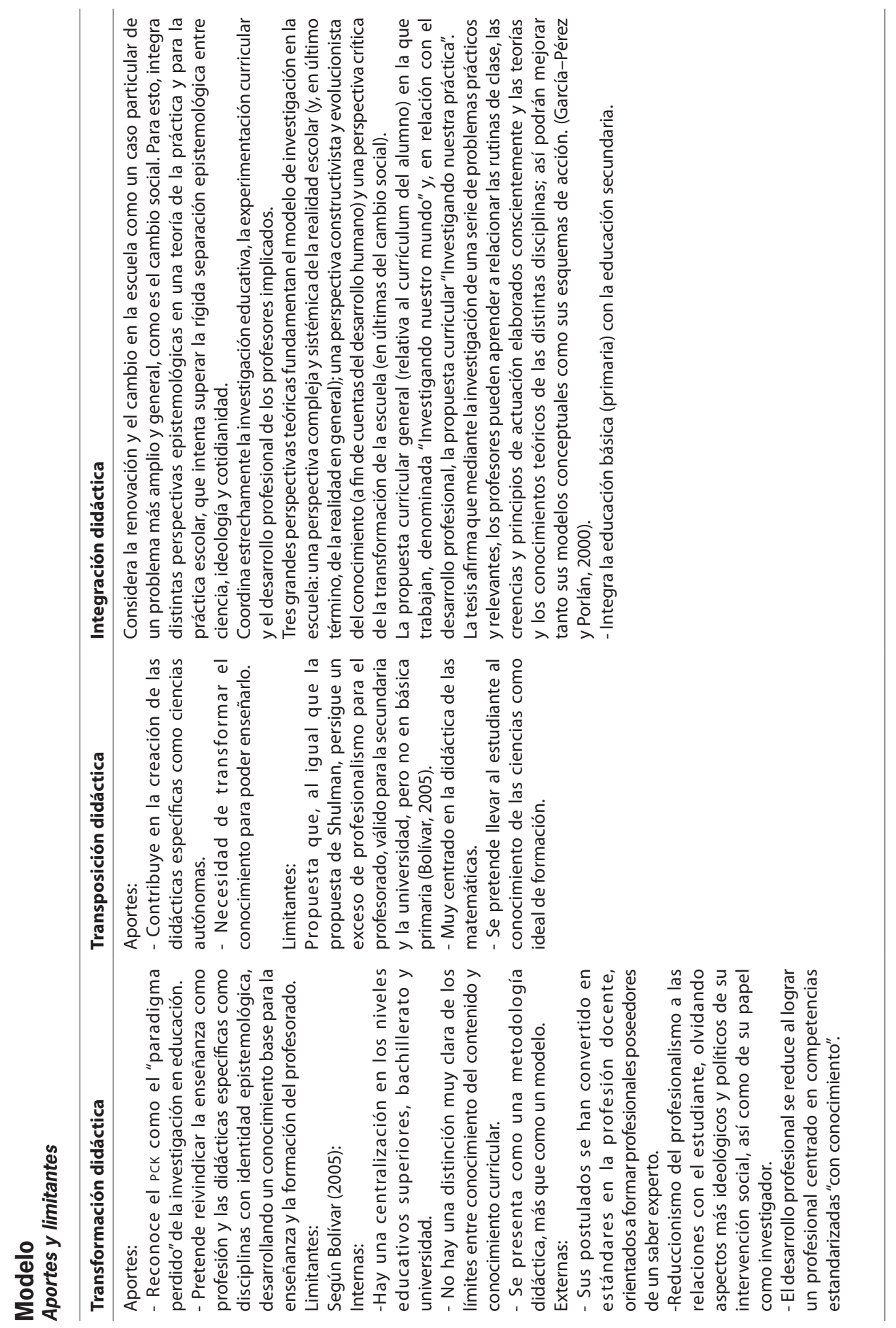


Como se observa en la Figura 1, el CDC tiene un componente personal de cada docente que es crítico en su comportamiento y prácticas educacionales, el cual estaría conformado por sus creencias y opiniones sobre qué es enseñar y aprender,y por sus experiencias prácticas personales, las cuales están basadas en sus experiencias tempranas como estudiante al ver a sus profesores enseñar. Estas opiniones e imágenes conforman un sistema de creencias con una función adaptativa, útil para comprender el desempeño docente (al planificar, seleccionar instrumentos cognitivos, y tomar decisiones) y desempeñan un papel crucial en la formación docente, ya que son difíciles de cambiar en la medida que son más antiguas (MorineDershvier y Kent, 1999 y Marcelo, 2005). Magnusson et al. (1999) consideran que las relaciones entre los conocimientos y creencias sobre la materia o contenido, lo pedagógico del currículo, el contexto y lo pedagógico del contenido incluyen orientaciones para la enseñanza de las ciencias que determinan los siguientes conocimientos: a) del currículo de ciencias (metas y objetivos, y programas curriculares específicos en relación con los planteados en сHEm Study, свA, Chem Com, Salters, Chemistry in Context, etc.) (Gabel, 1998); b) de las creencias y preconcepciones de los estudiantes sobre las ciencias (requerimientos para el aprendizaje, áreas de dificultad para el estudiantado); c) de la evaluación en ciencias (dimensiones del aprendizaje de las ciencias, y de los métodos con que se evalúa el aprendizaje de las ciencias) y d) de las estrategias instruccionales (para materias específicas en el caso de las ciencias, por ejemplo, basadas en el cambio conceptual, y estrategias para tópicos específicos usando modelos o analogías).

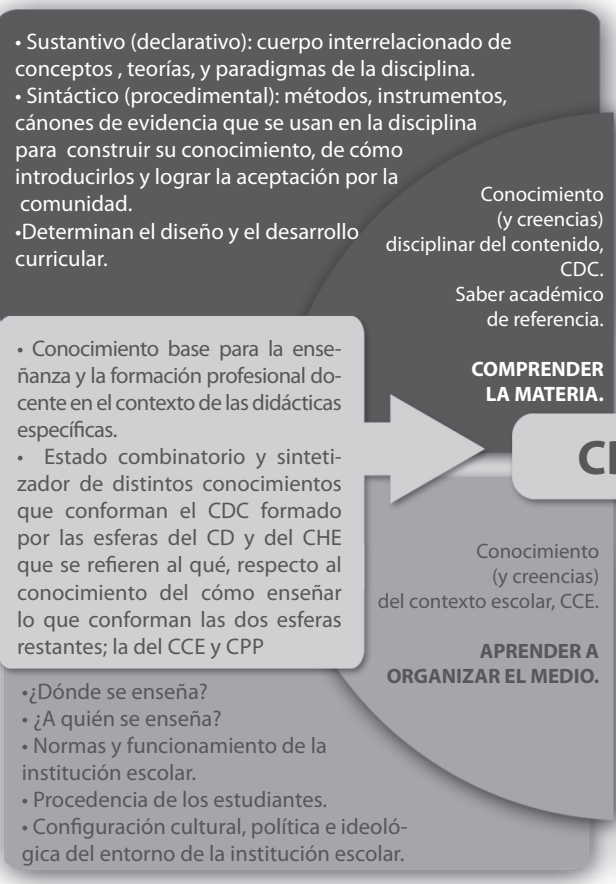

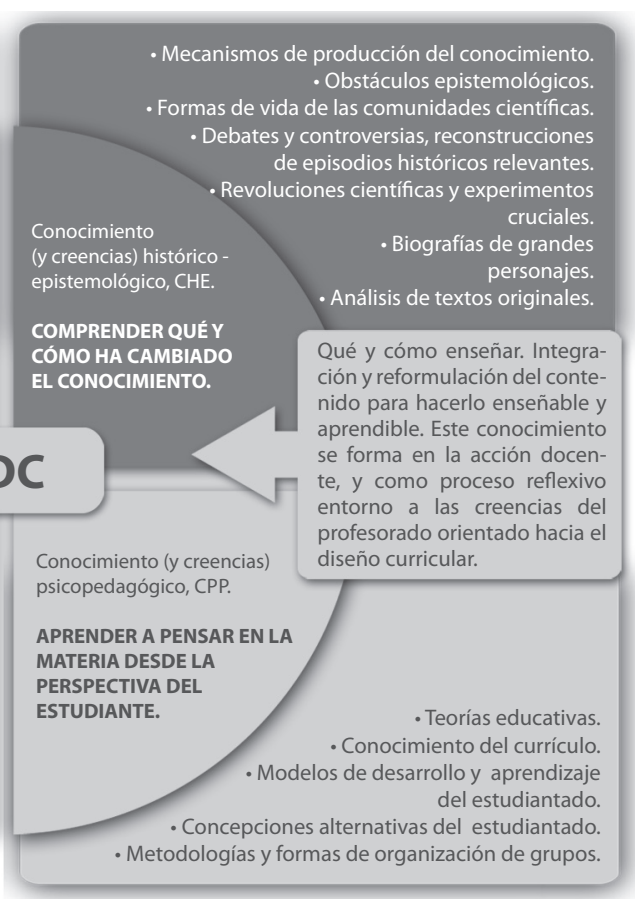

Figura 1: Integración de los tipos de conocimientos-creencias docentes para formar el CDC. 
Al examinar la Figura 1, sobre la integración de los tipos de conocimientos-creencias docentes para formar el conocimiento didáctico del contenido, es posible que cada docente presente propuestas asimétricas en las cuales valore más unos conocimientos que otros y, como lo muestran Abell y Lederman (2007), son campos de relaciones poco investigadas. Por su formación o por sus intereses a la hora de diseñar curricularmente una unidad didáctica de enseñanza-aprendizaje es posible que un profesor no integre de igual manera y valoración los cuatro conocimientoscreencias, haciendo más énfasis en uno que otro, es decir, podemos encontrar casos en que, por ejemplo, el orden de importancia y cantidad de conocimientos sea: conocimiento del contenido $>$ conocimiento histórico-epistemológico $>$ COnocimiento pedagógico $>$ conocimiento del contexto. En otros casos podríamos tener: conocimiento pedagógico > conocimiento del contenido $>$ conocimiento del contexto > conocimiento históricoepistemológico. Esta integración refuerza la idea que no basta con "saber bien la materia" para enseñar profesionalmente un contenido, se requiere integrar otros conocimientos, pero los conocimientoscreencias y la preponderancia que den de uno de estos conocimientos sobre los otros determinará que el CDC resultante influya decididamente en el qué y cómo enseñar.

Se puede decir, como lo proponen a manera de hipótesis Magnusson, et al. (1999), que hay diferentes rutas o múltiples caminos para desarrollar el CDC para tópicos específicos de enseñanza, ya que se integran con mayor énfasis unos conocimientos que otros, por lo que es necesario que en la formación docente: a) se le ayude a reflexionar sobre sus conocimientos y creencias preexistentes; b) concienciar sobre el CDC como un campo especifico del dominio profesional docente, resultante de la integración de cuatro distintos conocimientos, haciendo énfasis en influencias de estos conocimientos-creencias, según el tópico a enseñar, como en su formación previa; c) la necesidad de situar las experiencias de aprendizaje en el entendimiento del contexto de enseñanza y d) que establecer un puente cognitivo entre lo que se pretende enseñar y lo que ya sabe el estudiante (lo cual es producto de sus preconcepciones) requiere un diseño de unidades didácticas para lo cual el CDC es fundamental.

En la formación docente, estos cuatro conocimientos-creencias no se deben introducir curricularmente de una manera fija como reglas o información o como simple suma de conocimientos, es decir, modelos como el tradicionalmente conocido "cachucha pedagógica"-en el que el conocimiento preponderante es el disciplinar con un agregado de pinceladas de los otros conocimientos - los cuales deben ser fuertemente criticados.

Por último, se puede decir que los maestros de ciencia no existen en estados fijos de los modelos transformativos o integrativos de una vez y para siempre, sino en un lugar en el transcurso del continuo entre los modelos integrador y transformativo, en el que no sólo su formación inicial, sino también su desarrollo profesional en algunos casos ha sido más suma-mixtura, que integración-combinatoria de los cuatro conocimientos-creencias analizados en la Figura 1. 


\section{Las Representaciones de Contenido, ReCo, y los Repertorios de Experiencia Profesional Didáctica, ReEpd, como instrumentos complementarios de determinación del CDC}

Muchas investigaciones han mostrado que el CDC es un constructo complejo y no generalizable en sentido estricto, siendo decepcionante que los esfuerzos de las investigaciones todavía no hayan proporcionado descripciones detalladas de CDC de profesores individuales o grupales (Gess-Newsome y Lederman, 1999, Loughran, Berry y Mulhall, 2006), siendo una de sus causas que su reconocimiento se obtenga únicamente por medio del efecto acumulativo de ir reflexionando en torno a las construcciones historias narrativas sobre cómo el profesorado construye y enseña el contenido en unidades didácticas. Por consiguiente, no es fácil realizar su seguimiento, no sólo porque el desarrollo es gradual y ocurre en periodos extendidos de tiempo, sino por el poco conocimiento de instrumentos adecuados para la recolección de información que eviten llegar a reduccionismos y simplificaciones de la interacción del contenido y la didáctica.

También los anteriores autores han destacado que existen pocos ejemplos concretos de CDC en la literatura, lo que hace difícil que los profesores de ciencia tengan acceso a éste a manera de modelos significativos para mejorar su práctica. Por tanto, la misma noción de CDC sigue siendo algo evasiva y requiere un lenguaje compartido para tener acceso y apoyar las ideas fundamentales de modo que este concepto pueda ser entendido y valorado de mejor manera.
Loughran, Berry y Mulhall (2006), como resultado de entrevistas individuales y de grupo, talleres y observaciones con el profesorado de ciencias durante varios años, desarrollaron un portafolio de captura que representa los aspectos más importantes del CDC de maestros exitosos de ciencias. Este formato está conformado por Content Representation, CoRe, articulada con Pedagogical and Professional-experience Repertoires, PaP-eRs, que nosotros llamaremos: Representaciones de Contenido, ReCo, y Repertorios de Experiencia Profesional Didáctica, ReEpd. Estos instrumentos permiten comparar lo que los docentes conocen y creen acerca de los contenidos más importantes a enseñar y lo que ellos reflexionan en sus historias narrativas de lo hecho en las aulas de clase.

La ReCo proporciona una descripción de la manera en que un grupo dado de profesores conceptúa el contenido de un tema particular de enseñanza. La ReCo se desarrolla pidiendo a los profesores pensar sobre lo que consideran: las grandes ideas asociadas al contenido que van a enseñar, las cuales se refieren a las ideas de ciencia que los profesores ven como cruciales para que los estudiantes desarrollen su comprensión del contenido. Luego, se discuten y consensúan estas grandes ideas, refinándolas y colocándolas en columnas verticales de un cuadro o matriz, que más tarde, se cruzan con indicadores constructivistas fundamentales en la integración del CDC, como se ve en la Tabla 2, sobre la cual hemos hecho algunos ajustes siguiendo lo propuesto por Reyes y Garritz (2006) y Garritz (2007).

Por su parte, el ReEpd es una evaluación narrativa del CDC de un maestro que resalta un aspecto del contenido 
de las ciencias que ha sido enseñado en relación con lo propuesto en la ReCo. En algunos casos, el ReEpd puede ser una construcción colectiva entre varios docentes, aunque lo mejor es presentarse de manera individual expresada en un diario del profesor. El ReEpd se redacta para desempaquetar los conocimientos y creencias de un docente en torno a la práctica del aula y, en concreto, sobre un aspecto particular del contenido. Se piensa que el ReEpd representa lo que el docente está razonando acerca de sus acciones pedagógicas del contenido en las aulas.

\begin{tabular}{|c|c|c|c|}
\hline \multirow{2}{*}{ Representación del Contenido, ReCo } & \multicolumn{3}{|c|}{ Ideas o conceptos más importantes a enseñar } \\
\hline & A: & D: & E: \\
\hline \multicolumn{4}{|l|}{$\begin{array}{l}\text { ¿Qué intenta que aprendan sus estudiantes } \\
\text { sobre esta idea? }\end{array}$} \\
\hline \multicolumn{4}{|l|}{$\begin{array}{l}\text { ¿Por qué es importante que los estudiantes } \\
\text { sepan esto? }\end{array}$} \\
\hline \multicolumn{4}{|l|}{$\begin{array}{l}\text { ¿Qué cree que le faltaría saber a los estudiantes } \\
\text { sobre esta idea? }\end{array}$} \\
\hline \multicolumn{4}{|l|}{$\begin{array}{l}\text { ¿Cuáles son las dificultades y limitaciones } \\
\text { asociadas con la enseñanza de esta idea? }\end{array}$} \\
\hline \multicolumn{4}{|l|}{$\begin{array}{l}\text { ¿Qué preconcepciones o ideas alternativas } \\
\text { (errores conceptuales) tienen los estudiantes } \\
\text { sobre esta idea y cómo influyen en la } \\
\text { enseñanza? }\end{array}$} \\
\hline \multicolumn{4}{|l|}{$\begin{array}{l}\text { Otros factores que influyen en la enseñanza } \\
\text { de esta idea. Por ejemplo, a nivel de normas } \\
\text { y funcionamiento de la institución escolar, } \\
\text { procedencia de los estudiantes, configuración } \\
\text { cultural, política e ideológica del entorno de la } \\
\text { institución escolar, del diseño curricular y del } \\
\text { trabajo entre docentes. }\end{array}$} \\
\hline \multicolumn{4}{|l|}{$\begin{array}{l}\text { 7. ¿Qué procedimientos o estrategias de } \\
\text { enseñanza emplea para que los estudiantes se } \\
\text { comprometan con esta idea? }\end{array}$} \\
\hline \multicolumn{4}{|l|}{$\begin{array}{l}\text { 8. ¿Qué formas de comprobar (evaluación, } \\
\text { coevaluación y autoevaluación) el } \\
\text { entendimiento o confusión de los estudiantes } \\
\text { acerca de esta idea utiliza? }\end{array}$} \\
\hline $\begin{array}{l}\text { 9. ¿Qué conocimientos sobre historia y } \\
\text { epistemología de esta idea conoce? Por } \\
\text { ejemplo, mecanismos de producción del } \\
\text { conocimiento, vida de las comunidades } \\
\text { científicas, debates y controversias, } \\
\text { reconstrucciones de episodios históricos } \\
\text { relevantes, revoluciones científicas y } \\
\text { experimentos cruciales, biografías de grandes } \\
\text { personajes. }\end{array}$ & & & \\
\hline
\end{tabular}

Tabla 2: Cómo identificar la Representación del Contenido de enseñanza. 
Loughran, Berry, y Mulhall (2006) nos dicen que un ReEpd varía dependiendo de lo que se está representando, por ejemplo, algunos ReEpd son representaciones de la perspectiva de un estudiante; otros del maestro, algunos toman el formato de una entrevista; otros una observación del aula o el pensamiento inherente en un maestro que refleja la naturaleza problemática de un concepto dado, mientras otros resaltan preocupaciones sobre el plan de estudios. Como una consecuencia, el formato de un ReEpd es sensible al tipo de situación que está intentando retratar, algunos usan llamadas al margen para atraer la atención a casos específicos que podrían pasarse por alto y que son importantes para quienes lo redactan. La combinación de las ReCo y los ReEpd son un recurso de identificación y representación poderosa, accesible y útil del CDC que relacionan teoría y práctica y son una invitación al profesorado (en formación, en ejercicio, así como educadores de maestros de ciencias) a explicitar e identificar qué es lo que necesitan saber y pensar cuando enseñan un nuevo tema; por ejemplo, ¿qué grandes ideas se deben enseñar a un grupo particular de estudiantes? ¿Qué se debe esperar que los estudiantes aprendan? ¿Qué procedimientos de enseñanza ayudarán a un grupo de estudiantes entender una gran idea en particular? Por último, un Recurso de Folio no se piensa como un documento-syllabus del plan de estudios, aunque puede formar parte de la relación teoríapráctica del diseño microcurricular expresado en el Syllabus.

\section{La formación del CDC en el profesorado en niveles o gradientes evolutivos de desarrollo profesional}

Como vimos en el apartado anterior, la identificación del CDC del profesorado como proceso de explicitación de las ReCo y su contrastación con los ReEpd (que relacionan lo que se piensa que se debe enseñar con lo que se realiza en la práctica) han sido utilizadas como estrategias de desarrollo profesional del profesorado tanto en formación como en ejercicio. Sin embargo, no es la única herramienta de construcción del CDC. De Jong, Veal, y Van Driel (2003), fundamentados en los resultados de la literatura, sugieren que el CDC puede ser desarrollado por análisis de las experiencias de enseñanza en combinación con talleres específicos en procesos longitudinales con pocos docentes, aunque sean casi inexistentes las experiencias publicadas en este sentido. A partir de la anterior idea, estos autores han diseñado un curso (de características constructivistas) de desarrollo del profesorado de química en el cual se articula la formación en lo disciplinar (materia o disciplina de base = química) (Subject Matter Knowledge, sMK) y el CDC (Pedagogical Content Knowledge, Рск) de manera integrada en cinco etapas: a) discusión de sus experiencias tempranas como aprendiz y como profesores en formación, en temas o contenidos específicos de conocimiento; b) discusiones del conocimiento disciplinar de base desde la perspectiva pedagógica, usando artículos de la literatura de investigaciones educativas acerca de la enseñanza y el aprendizaje del tópico elegido; c) expresiones de intención de 
enseñanza, discutiendo capítulos de libros de texto y preparando planes (unidades didácticas) de enseñanza de un tópico interesante; d) enseñanza del tópico elegido en contextos escolares específicos y e) reflexión sobre el conocimiento de base y del CDC por discusión de los reportes individuales de las lecciones dadas en torno a la unidad didáctica diseñada. Todo este proceso se lleva a cabo con discusiones ayudadas por mentores e investigadores.

De igual manera, el Proyecto Cero, liderado por David Perkins de la Escuela de Posgrado en Educación de la Universidad de Harvard, conocido como Enseñanza para la Comprensión, EpC, insiste en el desarrollo profesional del profesorado en la medida en que se compromete con el aprendizaje para el desempeño flexible de competencias para pensar y actuar a partir de lo que saben los estudiantes. Cuatro preguntas centrales acerca de la Enseñanza conforman la propuesta: ¿qué tópicos vale la pena comprender? ¿Qué aspectos de esos tópicos deben ser comprendidos? ¿Cómo podemos promover la comprensión? Y ¿Cómo podemos averiguar lo que comprenden los estudiantes? (Stone, 1999), preguntas que se estructuran en cuatro dimensiones y sus rasgos:

Para cada rasgo hay cuatro niveles de comprensión del estudiantado (Tabla 4), a saber: ingenua (nivel 1), principiante (nivel 2), aprendiz (nivel 3) y maestría (nivel 4).

\begin{tabular}{llll}
\hline Contenido & Métodos & Propósitos & $\begin{array}{l}\text { Formas de } \\
\text { comunicación }\end{array}$ \\
\hline $\begin{array}{l}\text { A. Creencias Intuitivas } \\
\text { transformadas. }\end{array}$ & A. Sano escepticismo. & $\begin{array}{l}\text { A. Conciencia de } \\
\text { los propósitos del } \\
\text { conocimiento. }\end{array}$ & $\begin{array}{l}\text { A. Buen manejo de los } \\
\text { géneros de desempeño. }\end{array}$ \\
\hline $\begin{array}{l}\text { B. Redes } \\
\text { conceptuales } \\
\text { coherentes y ricas. }\end{array}$ & $\begin{array}{l}\text { B. Construir conocimientos } \\
\text { en el saber. }\end{array}$ & $\begin{array}{l}\text { B. Usos del } \\
\text { conocimiento. }\end{array}$ & $\begin{array}{l}\text { B. Uso efectivo de } \\
\text { sistemas de símbolos. }\end{array}$ \\
\hline & $\begin{array}{l}\text { C. Utilización de } \\
\text { criterios para validar } \\
\text { el conocimiento en el } \\
\text { dominio. }\end{array}$ & $\begin{array}{l}\text { C. Manejo y } \\
\text { autonomía. }\end{array}$ & $\begin{array}{l}\text { C. Consideración del } \\
\text { público y el contexto. }\end{array}$ \\
\hline
\end{tabular}

Tabla 3: Dimensiones y rasgos de la comprensión.

\begin{tabular}{|c|c|c|c|c|}
\hline & $\begin{array}{l}\text { Comprensión } \\
\text { ingenua }\end{array}$ & $\begin{array}{l}\text { Comprensión } \\
\text { de principiante }\end{array}$ & $\begin{array}{l}\text { Comprensión } \\
\text { de aprendiz }\end{array}$ & $\begin{array}{l}\text { Comprensión } \\
\text { de maestría }\end{array}$ \\
\hline $\begin{array}{l}\text { Desempeños } \\
\text { arraigados }\end{array}$ & $\begin{array}{l}\text { En conocimientos } \\
\text { intuitivos. }\end{array}$ & $\begin{array}{l}\text { Rituales de } \\
\text { pruebas y de la } \\
\text { escolarización. }\end{array}$ & $\begin{array}{l}\text { Conocimiento } \\
\text { disciplinario y } \\
\text { modalidades de } \\
\text { pensamiento. }\end{array}$ & $\begin{array}{l}\text { Integradores, creativos y } \\
\text { críticos. }\end{array}$ \\
\hline $\begin{array}{l}\text { Construcción } \\
\text { del } \\
\text { conocimiento }\end{array}$ & $\begin{array}{l}\text { Como proceso no } \\
\text { problémico. }\end{array}$ & $\begin{array}{l}\text { Ideas con } \\
\text { conexiones } \\
\text { simples, de } \\
\text { ensayo con } \\
\text { procedimientos } \\
\text { mecánicos paso } \\
\text { a paso. }\end{array}$ & $\begin{array}{l}\text { Algo complejo con } \\
\text { procedimientos } \\
\text { y criterios } \\
\text { prototípicamente } \\
\text { usados por } \\
\text { expertos del } \\
\text { dominio del saber. }\end{array}$ & $\begin{array}{l}\text { Algo complejo impulsado } \\
\text { a menudo por marcos y } \\
\text { visiones que resultan de } \\
\text { la argumentación pública } \\
\text { de las comunidades de } \\
\text { diversos dominios del } \\
\text { saber. }\end{array}$ \\
\hline
\end{tabular}




\begin{tabular}{|c|c|c|c|c|}
\hline $\begin{array}{l}\text { Relación escuela } \\
\text { y cotidianidad: }\end{array}$ & $\begin{array}{l}\text { No ven la } \\
\text { relación y no } \\
\text { consideran } \\
\text { los propósitos } \\
\text { y usos del } \\
\text { conocimiento. }\end{array}$ & $\begin{array}{l}\text { Sirven para } \\
\text { describir la } \\
\text { naturaleza. }\end{array}$ & $\begin{array}{l}\text { Los desempeños } \\
\text { iluminan la } \\
\text { relación entre } \\
\text { conocimiento } \\
\text { disciplinar y } \\
\text { vida cotidiana, } \\
\text { examinando sus } \\
\text { consecuencias. }\end{array}$ & $\begin{array}{l}\text { Se usa el conocimiento } \\
\text { para reinterpretar el } \\
\text { mundo que lo rodea. }\end{array}$ \\
\hline $\begin{array}{l}\text { Validación de los } \\
\text { desempeños: }\end{array}$ & $\begin{array}{l}\text { No muestran } \\
\text { signos de } \\
\text { dominio de } \\
\text { lo que saben } \\
\text { los alumnos. } \\
\text { Desempeños } \\
\text { no reflexivos } \\
\text { en la } \\
\text { comunicación } \\
\text { con los demás. }\end{array}$ & $\begin{array}{l}\text { Depende de } \\
\text { la autoridad } \\
\text { externa más } \\
\text { que de criterios } \\
\text { de racionalidad } \\
\text { consensuada en } \\
\text { la comunidad. }\end{array}$ & $\begin{array}{l}\text { Expresión y } \\
\text { comunicación } \\
\text { flexible y } \\
\text { adecuada al } \\
\text { conocimiento. }\end{array}$ & $\begin{array}{l}\text { Van más allá de } \\
\text { demostrar la } \\
\text { comprensión disciplinaria } \\
\text { y muestran una } \\
\text { conciencia crítica } \\
\text { metadisciplinar e } \\
\text { interdisciplinar. }\end{array}$ \\
\hline
\end{tabular}

Tabla 4: Niveles de comprensión del estudiantado.

La Tabla 5 presenta una matriz de evaluación del diseño curricular mediante la Enseñanza para la Comprensión:

\section{Evaluación del diseño curricular}

\begin{tabular}{|c|c|c|c|c|}
\hline Dimensiones & $\begin{array}{l}\text { Comprensión } \\
\text { ingenua }\end{array}$ & $\begin{array}{l}\text { Comprensión } \\
\text { de principiante }\end{array}$ & $\begin{array}{l}\text { Comprensión } \\
\text { de aprendiz }\end{array}$ & $\begin{array}{l}\text { Comprensión } \\
\text { de maestría }\end{array}$ \\
\hline $\begin{array}{l}\text { Hilos conductores: } \\
\text { preguntas claras } \\
\text { que guían la } \\
\text { comprensión y } \\
\text { son centrales en la } \\
\text { disciplina. }\end{array}$ & $\begin{array}{l}\text { No son } \\
\text { preguntas o, } \\
\text { si las hay, son } \\
\text { cerradas. No } \\
\text { son centrales } \\
\text { y no están } \\
\text { conectados } \\
\text { con las demás } \\
\text { dimensiones de } \\
\text { la comprensión. }\end{array}$ & $\begin{array}{l}\text { Algunas son } \\
\text { preguntas, pero } \\
\text { no son muy } \\
\text { centrales y poco } \\
\text { diferenciadas } \\
\text { de las metas y } \\
\text { desempeños. }\end{array}$ & $\begin{array}{l}\text { Son preguntas } \\
\text { claras, la mayoría } \\
\text { abiertas, que se } \\
\text { diferencian de las } \\
\text { metas y los tópicos, } \\
\text { pero que podrían } \\
\text { expresarse mejor. }\end{array}$ & $\begin{array}{l}\text { Claramente } \\
\text { enmarcadas, abiertas } \\
\text { y centrales de su } \\
\text { disciplina, organizan } \\
\text { la exploración de los } \\
\text { tópicos y las metas. }\end{array}$ \\
\hline $\begin{array}{l}\text { Tópicos } \\
\text { generativos: } \\
\text { contenidos } \\
\text { centrales de una } \\
\text { disciplina. }\end{array}$ & $\begin{array}{l}\text { No son del } \\
\text { interés del } \\
\text { profesor ni } \\
\text { interesante para } \\
\text { el estudiantado } \\
\text { y no son temas } \\
\text { centrales para } \\
\text { la disciplina ni } \\
\text { muestran una } \\
\text { relación con los } \\
\text { hilos y las metas } \\
\text { de desempeño. }\end{array}$ & $\begin{array}{l}\text { Son más o menos } \\
\text { interesantes para } \\
\text { el profesor, de } \\
\text { alguna forma son } \\
\text { centrales para la } \\
\text { disciplina, pero se } \\
\text { pueden expresar } \\
\text { de forma más } \\
\text { interesante para } \\
\text { el estudiantado, } \\
\text { parecen organizar } \\
\text { los hilos y las } \\
\text { metas. }\end{array}$ & $\begin{array}{l}\text { Son interesantes } \\
\text { para el profesor, } \\
\text { son temas centrales } \\
\text { para la disciplina } \\
\text { y enganchan a los } \\
\text { estudiantes; sin } \\
\text { embargo; pueden } \\
\text { expresarse con } \\
\text { mayor claridad, } \\
\text { pero pueden } \\
\text { repetirse. }\end{array}$ & $\begin{array}{l}\text { Son claramente la } \\
\text { pasión del profesor, } \\
\text { son conceptos } \\
\text { centrales para } \\
\text { la disciplina, } \\
\text { enganchan } \\
\text { fácilmente a los } \\
\text { estudiantes, bien } \\
\text { organizados para su } \\
\text { exploración bajo los } \\
\text { hilos y metas claras y } \\
\text { unívocas. }\end{array}$ \\
\hline
\end{tabular}




\begin{tabular}{ll}
\hline & Si existen no \\
& están claras, o \\
Metas de & son restringidas \\
comprensión & o muy amplias, \\
en cada tópico & difíciles de \\
generativo. & valorar.
\end{tabular}

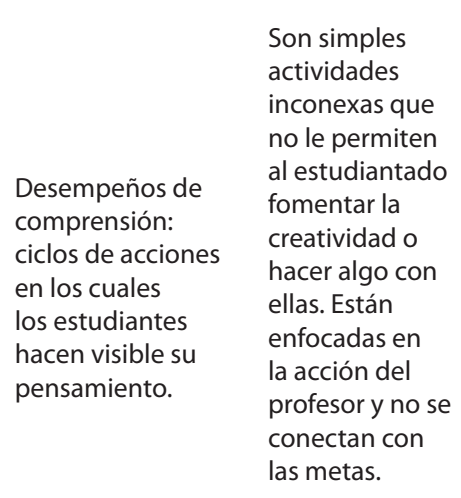

Más o menos
claras, pero no
son un número
manejable,
demasiado rígidas
o amplias para
evaluar.

Actividades que no muestran el saber hacer del estudiantado a partir de sus conocimientos. Las actividades están centradas en el profesor, aunque muestren una secuencia lógica, no se conectan claramente con las metas.

\author{
Están claras y no \\ se repiten, aunque \\ algunas se puedan \\ condensar para \\ evaluar mejor; \\ ayudan a centrar \\ los tópicos.
}

Muy claras y no

se repiten en cantidad, fácilmente manejable para su evaluación.

Involucran a los
estudiantes en
hacer algo y pensar
creativamente con
sus conocimientos,
pero algunos
podrían estar mejor
desarrollados, la
mayoría se centra
en la actividad de
los estudiantes
y se desarrollan
en secuencias de
investigación y
síntesis.

\author{
Son claramente \\ eventos en \\ los cuales los \\ estudiantes piensan \\ creativamente con. \\ Se centran en los \\ estudiantes y están \\ bien organizados \\ en secuencias \\ de exploración, \\ investigación y \\ síntesis. Están bien \\ conectadas con sus \\ metas.
}

\begin{tabular}{|c|c|c|c|c|}
\hline $\begin{array}{l}\text { Evaluación } \\
\text { continua: ciclos de } \\
\text { retroalimentación } \\
\text { formal e informal } \\
\text { en torno a los } \\
\text { desempeños. }\end{array}$ & $\begin{array}{l}\text { No hay un ciclo } \\
\text { continuo de } \\
\text { evaluación, } \\
\text { sólo hay una } \\
\text { evaluación } \\
\text { final. No hay } \\
\text { autoevaluación, } \\
\text { no se usan } \\
\text { formatos } \\
\text { formales, ni } \\
\text { informales. No } \\
\text { hay criterios } \\
\text { de calidad } \\
\text { compartidos. }\end{array}$ & $\begin{array}{l}\text { Hay algunas } \\
\text { evaluaciones, pero } \\
\text { están centradas } \\
\text { en el profesor. No } \\
\text { se presentan de } \\
\text { forma que ayuden } \\
\text { a los estudiantes } \\
\text { a desarrollar su } \\
\text { comprensión, es } \\
\text { necesario realizar } \\
\text { la autoevaluación } \\
\text { y los instrumentos. } \\
\text { No hay criterios } \\
\text { de calidad } \\
\text { públicamente } \\
\text { compartidos que } \\
\text { se relacionen } \\
\text { con las } \\
\text { dimensiones de la } \\
\text { comprensión. }\end{array}$ & $\begin{array}{l}\text { Organizadas } \\
\text { en ciclos que } \\
\text { parecen permitir } \\
\text { a los estudiantes } \\
\text { desarrollar la } \\
\text { comprensión en el } \\
\text { tiempo. Hay gran } \\
\text { variedad de formas } \\
\text { de autoevaluación } \\
\text { y evaluación de } \\
\text { pares con criterios } \\
\text { públicos, pero } \\
\text { deben relacionarse } \\
\text { más con las demás } \\
\text { dimensiones. }\end{array}$ & $\begin{array}{l}\text { Organizadas } \\
\text { claramente en ciclos } \\
\text { de retroalimentación } \\
\text { que le ayudan } \\
\text { al estudiantado } \\
\text { a desarrollar } \\
\text { comprensión en } \\
\text { el tiempo. Con } \\
\text { excelente balance de } \\
\text { formas de evaluación } \\
\text { con autoevaluación, } \\
\text { coevaluación y } \\
\text { metaevaluación. } \\
\text { Con instrumentos } \\
\text { formales e } \\
\text { informales y con } \\
\text { criterios públicos } \\
\text { de trabajo con } \\
\text { calidad que } \\
\text { relacionan distintas } \\
\text { dimensiones. }\end{array}$ \\
\hline
\end{tabular}

Tabla 5: Evaluación del diseño curricular. 
Por su parte, el grupo DIE de la Universidad de Sevilla, en complemento a lo ya descrito en la Tabla 1 (Porlán, 2003), ha planteado la formación inicial y permanente del profesorado centrándose en problemas de enseñanza de los contenidos, que han denominado Ámbitos de Investigación Profesional, AIP, que permiten el desarrollo del conocimiento profesional deseable a la manera de una hipótesis de evolución profesional (por niveles de formulación progresivamente más complejos, como se muestran en la Tabla 6, que es tomada de Martín del Pozo y Rivero (2001), y que evoluciona de un modelo didáctico tradicional a un modelo más constructivista e investigador.

\begin{tabular}{|c|c|c|c|}
\hline & Nivel de partida & Niveles intermedios & Nivel de referencia \\
\hline & $\begin{array}{l}\text { Visión cotidiana de } \\
\text { la enseñanza y del } \\
\text { papel del profesor. }\end{array}$ & $\begin{array}{l}\text { Profesor técnico y espontaneísta, capaz } \\
\text { de programar en secuencias cerradas de } \\
\text { actividades basado en objetivos. }\end{array}$ & $\begin{array}{l}\text { Conocimiento } \\
\text { profesional } \\
\text { transdisciplinar y práctico } \\
\text { que se construye } \\
\text { significativamente. }\end{array}$ \\
\hline $\begin{array}{l}\text { Conocimiento. } \\
\text { ¿Qué sabemos sobre } \\
\text { determinados tópicos } \\
\text { del currículo escolar? }\end{array}$ & Visión enciclopédica. & $\begin{array}{l}\text { Visiones compartimentalizadas y } \\
\text { jerarquizadas. }\end{array}$ & $\begin{array}{l}\text { Visión relativa, evolutiva } \\
\text { e integradora. }\end{array}$ \\
\hline $\begin{array}{l}\text { Las ideas del } \\
\text { alumnado. } \\
\text { ¿Cuál es la naturaleza } \\
\text { de las ideas del } \\
\text { estudiantado? }\end{array}$ & $\begin{array}{l}\text { Los estudiantes no } \\
\text { tienen ideas o éstas } \\
\text { no son relevantes } \\
\text { para incorporar los } \\
\text { conocimientos. }\end{array}$ & $\begin{array}{l}\text { Las ideas del estudiantado se consideran } \\
\text { errores que deben explicitarse y } \\
\text { sustituirse. El alumnado aprende por } \\
\text { descubrimiento espontáneo. }\end{array}$ & $\begin{array}{l}\text { Las ideas del } \\
\text { estudiantado como } \\
\text { conocimiento alternativo } \\
\text { con el que construyen } \\
\text { nuevos significados. }\end{array}$ \\
\hline $\begin{array}{l}\text { Finalidades. } \\
\text { ¿Cuál es el papel en la } \\
\text { formación básica del } \\
\text { estudiantado? }\end{array}$ & $\begin{array}{l}\text { Adquirir } \\
\text { conocimientos } \\
\text { científicos. }\end{array}$ & $\begin{array}{l}\text { Sustituir el conocimiento del } \\
\text { estudiantado por el conocimiento } \\
\text { científico. Desarrollar actitudes y } \\
\text { procedimientos científicos. }\end{array}$ & $\begin{array}{l}\text { Complejizar el } \\
\text { conocimiento cotidiano } \\
\text { del estudiantado. }\end{array}$ \\
\hline $\begin{array}{l}\text { Contenidos. } \\
\text { ¿Qué formulaciones } \\
\text { diferentes existen } \\
\text { de los contenidos } \\
\text { implicados? }\end{array}$ & $\begin{array}{l}\text { Los contenidos } \\
\text { como versión } \\
\text { simplificada, } \\
\text { reduccionista y } \\
\text { enciclopédica } \\
\text { de los conceptos } \\
\text { disciplinares. }\end{array}$ & $\begin{array}{l}\text { Los contenidos como transformación } \\
\text { didáctica de procesos y productos } \\
\text { disciplinares. } \\
\text { Integración de conocimientos } \\
\text { disciplinares y problemas socio- } \\
\text { ambientales. } \\
\text { Niveles de progresión entre lo cotidiano } \\
\text { y lo científico. } \\
\text { Expresión de los intereses y experiencias } \\
\text { del estudiantado. }\end{array}$ & $\begin{array}{l}\text { Integración de } \\
\text { informaciones } \\
\text { procedentes de fuentes } \\
\text { diversas. }\end{array}$ \\
\hline $\begin{array}{l}\text { Metodología. } \\
\text { ¿Cómo debería ser y } \\
\text { qué debería orientar } \\
\text { una secuencia de } \\
\text { actividades? }\end{array}$ & $\begin{array}{l}\text { Metodologías } \\
\text { transmisivas } \\
\text { (explicación más } \\
\text { ilustración). }\end{array}$ & $\begin{array}{l}\text { Metodologías duales basadas en } \\
\text { la explicación más actividades (de } \\
\text { aplicación, de verificación, de contraste, } \\
\text { espontáneas). } \\
\text { Metodologías inductivas. } \\
\text { Metodologías activistas. }\end{array}$ & $\begin{array}{l}\text { Metodologías basadas } \\
\text { en la investigación del } \\
\text { estudiantado a partir de } \\
\text { problemas relevantes en } \\
\text { el contexto escolar. }\end{array}$ \\
\hline $\begin{array}{l}\text { Evaluación. } \\
\text { ¿Qué modelos } \\
\text { de evaluación } \\
\text { existen y en qué se } \\
\text { fundamentan? }\end{array}$ & $\begin{array}{l}\text { Evaluación como } \\
\text { comprobación de } \\
\text { la adquisición de } \\
\text { conocimientos. }\end{array}$ & $\begin{array}{l}\text { Evaluación por medio de la consecución } \\
\text { de los objetivos. } \\
\text { Evaluación como participación del } \\
\text { estudiantado en la toma de decisiones } \\
\text { sobre la vida en el aula. }\end{array}$ & $\begin{array}{l}\text { Evaluación como } \\
\text { proceso de seguimiento } \\
\text { de la evolución real } \\
\text { de los conceptos del } \\
\text { estudiantado y de ajuste } \\
\text { de la enseñanza. }\end{array}$ \\
\hline
\end{tabular}

Tabla 6: Evolución de un modelo didáctico. 
En el nivel de referencia (deseable) planteado en la Tabla 6, un docente, al diseñar curricularmente un contenido específico de enseñanza, debería saber y saber hacer: a) un análisis didáctico de diferentes fuentes de información; b) una trama de problemas y contenidos asociados, formulados en diferentes niveles de complejidad en una hipótesis de progresión del conocimiento; c) Una posible secuencia de actividades según una metodología constructivista e investigativa y d) mecanismos para el ajuste entre la hipótesis de progresión del conocimiento escolar y la evolución real de las concepciones de los alumnos.

\section{La articulación de las tramas de contenido histórico-epistemológicas con las tramas de contexto- aprendizaje en el CDC en química}

Garritz y Trinidad-Velazco (2004) han encontrado que los estudios sobre el CDC en química son relativamente pocos y, apoyados en la revisión de Abell (2007), nosotros podríamos aseverar que son más referidos al campo del Conocimiento Disciplinar del Contenido, CDC (Subject Matter Knowledge, sмк), que en el CDC. La mayoría de los trabajos se han hecho con profesores en formación y particularmente quienes trabajan en educación primaria o en grados séptimo a décimo. Las temáticas trabajadas han estado centradas en pocos temas: en teoría atómica-molecular se ha trabajado con gases destacando las relaciones sustancia-elemento, densidad-presión del aire, mezclas-compuestos, elementos-átomos, compuestos-moléculas, cambio-conservación de la materia; mol-cantidad de sustancia, reacción química, equilibrio químico; relaciones de lo macro y micro. Destacamos los trabajos en CDC realizados por Loughran, Berry y Mulhall (2006) sobre teoría de partículas y reacciones químicas centrados en la realización de CoRe y PaP-eRs. Sin embargo, es fundamental decir que en campos como la química orgánica, la bioquímica o la química ambiental son inexistentes los trabajos investigativos sobre el CDC.

Atendiendo a estos campos poco explorados de la química y utilizando conceptos como el de trama conceptual y el de diseño, implementación y reflexión de contenidos didácticos (Mora y Parga, 2007), se establecen algunas orientaciones útiles para el desarrollo profesional didáctico. En nuestra propuesta intentamos hacer el análisis históricoepistemológico-científico, con el fin de hacer una posterior integración con lo contextual-psicopedagógico en dos tramas o momentos distintos esenciales para el diseño del contenido.

En la medida en que se da la integración de estos conocimientos es posible plantearse los contenidos de enseñanza que no sólo permiten plantearse los programas de la asignatura a enseñar (Syllabus), sino que, como dice Novak (1977), pueden servir como puente cognitivo para relacionar lo que se quiere enseñar con lo que el estudiantado trae en sus preconcepciones e ideas previas y en el cual las tramas articuladas en CDC no son más que un encuentro de integración entre lo que los estudiantes ya saben y lo que los profesores intentan enseñar mediante una propuesta de contenido que combina lo disciplinar con lo psicopedagógico. A diferencia del planteamiento de Novak, en el cual el puente cognitivo es dado por medio de un único concepto estructurante (visión que consideramos en ese sentido un poco rígida), en nues- 
tro caso el puente cognitivo no es un concepto estructurante, sino una trama flexible de conceptos, como lo sugiere Astolfi (2001). Las tramas de conceptos son flexibles, son una guía y no son para obligar al estudiante a hacer coincidir la ontogénesis con la filogénesis de los conocimientos. No se pretende establecer que las tramas sean dadas en forma lineal, pueden ser esféricas, en espiral; lo importante es que permiten pasar de un pensamiento simple del estudiante a uno más complejo, enriqueciendo su conocimiento.

Perspectivas de tramas conceptuales histórico-epistemológicas, como las que hemos planteado (Mora y Parga, 2007 y Parga y Martínez, 2007) o las presentadas por Martín del Pozo (1994), se dan en tres niveles de trama conceptual cada vez más complejas: nivel macroscópico, nivel asociado atómico-molecular y nivel cuántico, los cuales son concordantes con las tres revoluciones de la química que plantea Jensen (1998): composición molar, composición molecular-estructura, y composición eléctrica-estructura: (molar-molecular-eléctrico) -Tabla 7que son útiles a la hora de diseñar tramas didácticas integradoras.

Sin embargo, aunque estos análisis históricos-epistemológicos se han dado desde la mirada docente, no explicitan su relación con los desarrollos del pensamiento de los estudiantes de manera que nos permitieran la integración con lo contextual-psicopedagógico, por lo que creemos que si usáramos categorías en este último sentido, propuestas desde la EpC, se trabajarían en cuatro niveles del desempeño (competencias); o por ejemplo desde el trabajo de Shayer y Adey (1984), que utiliza niveles de desarrollo de pensamiento piagetianos, nos permitiría enfocarnos hacia visiones más integradas y consecuentes al CDC a la hora de diseñar propuestas curriculares dirigidas a la enseñanza. En ese sentido, una matriz combinada como se muestra en la Tabla 8, centrada en el concepto del cambio químico, (reacción química) podría ser una opción de desarrollo y experimentación futura a la hora de diseñar unidades didácticas en química.

\begin{tabular}{|c|c|c|c|}
\hline $\begin{array}{l}\text { Estructura de } \\
\text { la química }\end{array}$ & $\begin{array}{l}\text { Dimensión de composición y } \\
\text { estructura }\end{array}$ & Dimensión de energía & Dimensión de tiempo \\
\hline Nivel molar & $\begin{array}{l}\text { 1. Composición relativa de } \\
\text { substancias puras simples y } \\
\text { compuestas, soluciones y mezclas. } \\
\text { Designación empírica de alomorfos } \\
\text { (estado, color, forma de cristal, etc.). }\end{array}$ & $\begin{array}{l}\text { 4. Calorimetría, entropía y calor } \\
\text { de formación. Energía libre y } \\
\text { constante de equilibrio. }\end{array}$ & $\begin{array}{l}\text { 7. Leyes experimentales } \\
\text { de proporción. Parámetros } \\
\text { experimentales de } \\
\text { Arrhenius o entropías y } \\
\text { calores de activación. }\end{array}$ \\
\hline Nivel molecular & $\begin{array}{l}\text { 2. Fórmulas absolutas y } \\
\text { estructurales. Racionalización de } \\
\text { alomorfos como variaciones en } \\
\text { cualquier composición absoluta (los } \\
\text { polímeros) o estructura (isómeros). }\end{array}$ & $\begin{array}{l}\text { 5. Interpretación molecular } \\
\text { de la entropía. Interpretación } \\
\text { de calores de formación } \\
\text { en términos de calores de } \\
\text { atomización, promedios } \\
\text { de energías de enlace, etc. } \\
\text { Mecánicas moleculares. }\end{array}$ & $\begin{array}{l}\text { 8. Mecanismos de reacción } \\
\text { moleculares. Visión } \\
\text { molecular de entropías } \\
\text { de activación y complejos } \\
\text { activados. }\end{array}$ \\
\hline Nivel eléctrico & $\begin{array}{l}\text { 3. Fórmulas electrónicas (estructuras } \\
\text { de Lewis y configuración } \\
\text { electrónica). Variaciones en la } \\
\text { composición electrónica o nuclear } \\
\text { (iones e isótopos) o estructura } \\
\text { (estados excitados). }\end{array}$ & $\begin{array}{l}\text { 6. Cálculos de energías } \\
\text { basados en estructuras } \\
\text { electrónicas. Interpretación de } \\
\text { espectros. Cálculos de calores } \\
\text { de atomización, entropías } \\
\text { espectroscópicas, etc. }\end{array}$ & $\begin{array}{l}\text { 9. Mecanismos de } \\
\text { la reacción iónicos y } \\
\text { fotoquímicos. Efectos } \\
\text { isotópicos. Cálculo de } \\
\text { energías de activación. } \\
\text { Índices de reactividad } \\
\text { electrónicos. }\end{array}$ \\
\hline
\end{tabular}

Tabla 7: Revoluciones químicas planteadas por Jensen (1998). 


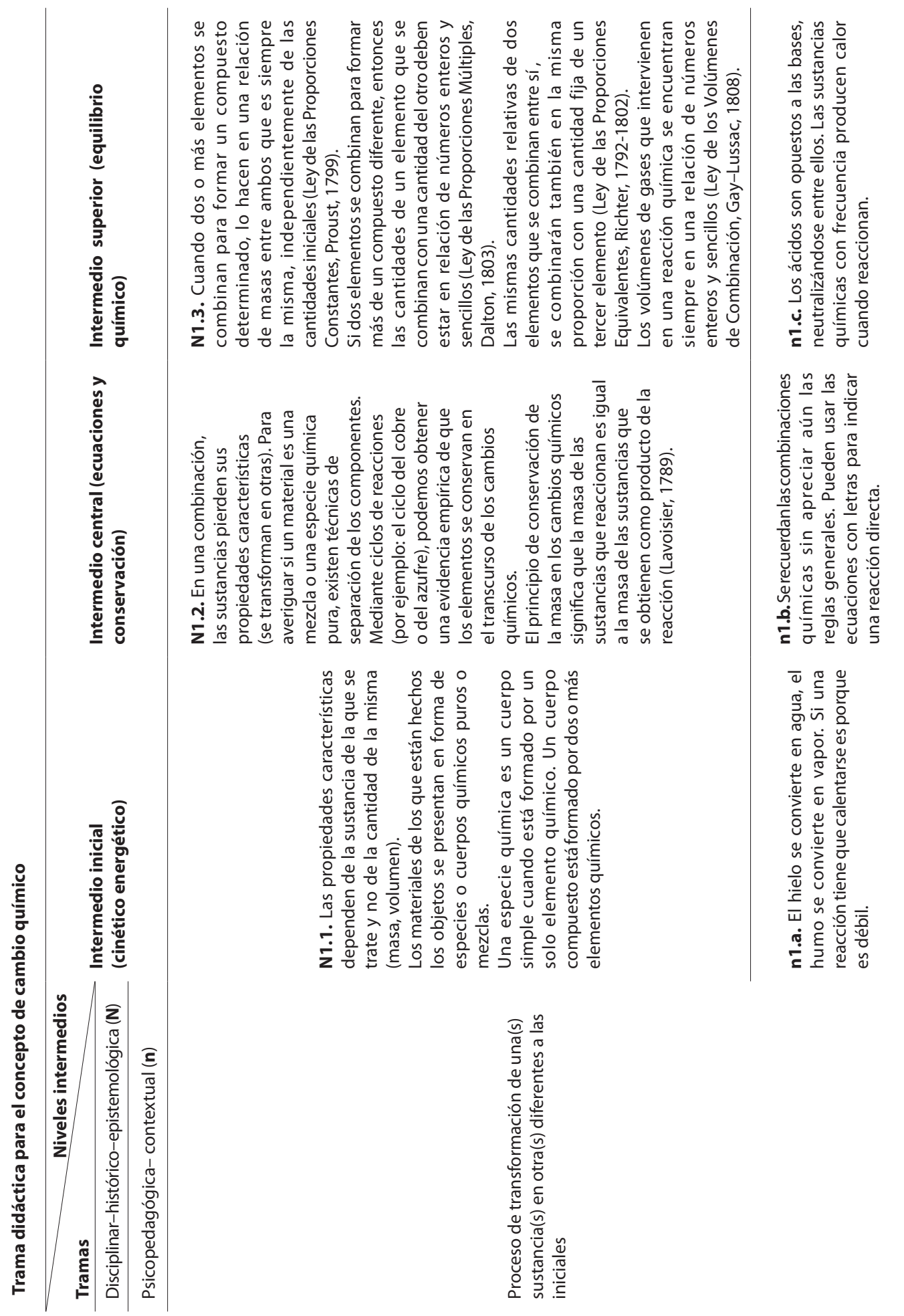




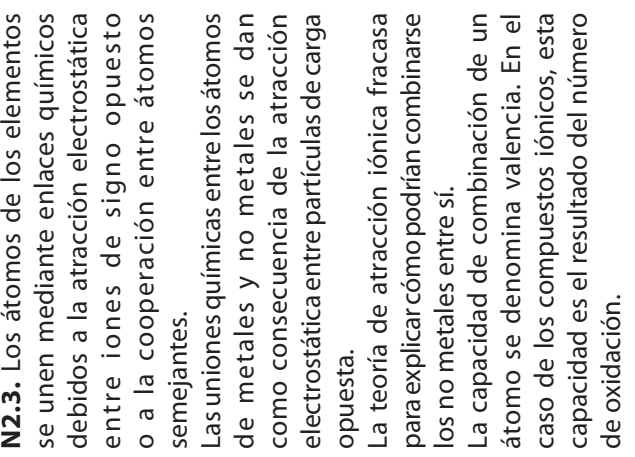

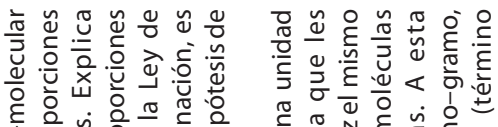

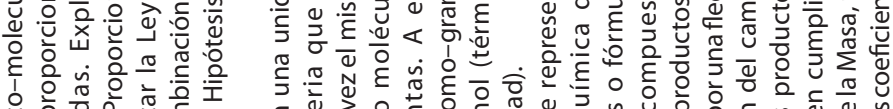

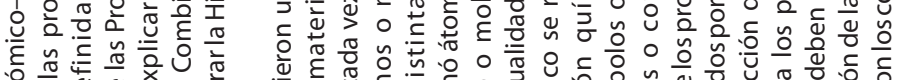

范

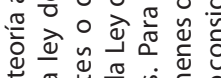

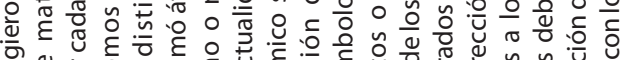

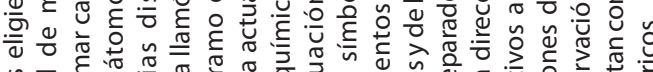

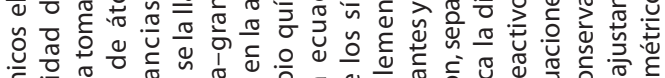

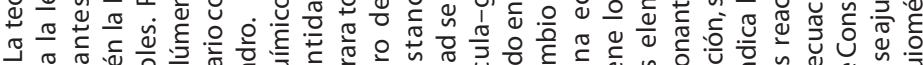

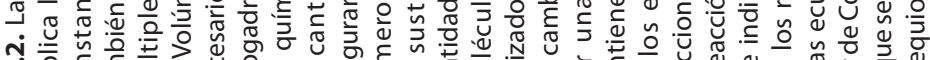
ง

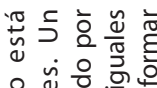

은

है.

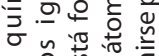

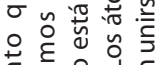

它

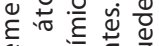

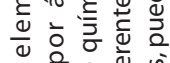

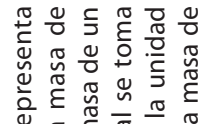

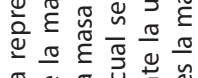

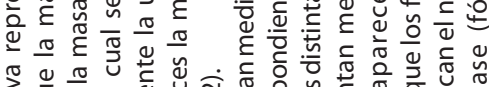

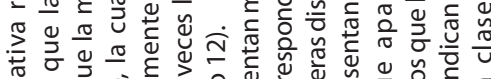

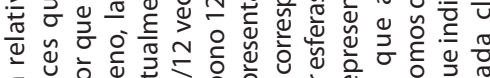

ช。

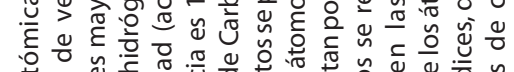

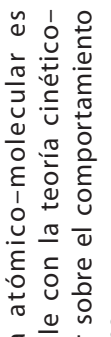

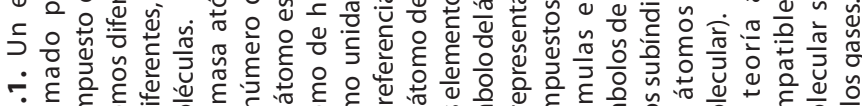

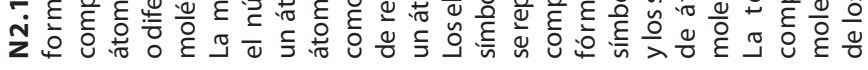

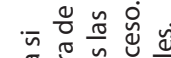

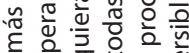

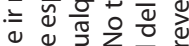

ปั

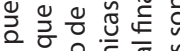

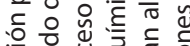

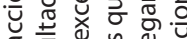
凹

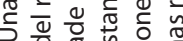

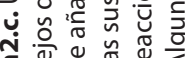

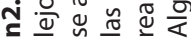

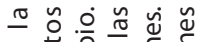

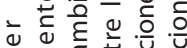

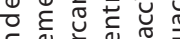

व ब ब

든

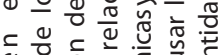
ร व

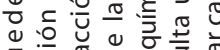
ᄀ - 전 은 늠 ำ

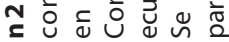

준

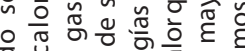
苟 0 人

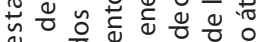

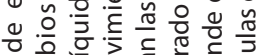
ह 으 त กำ

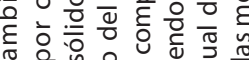
ษ

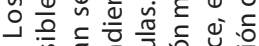

ণั

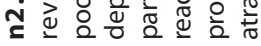

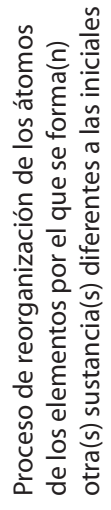




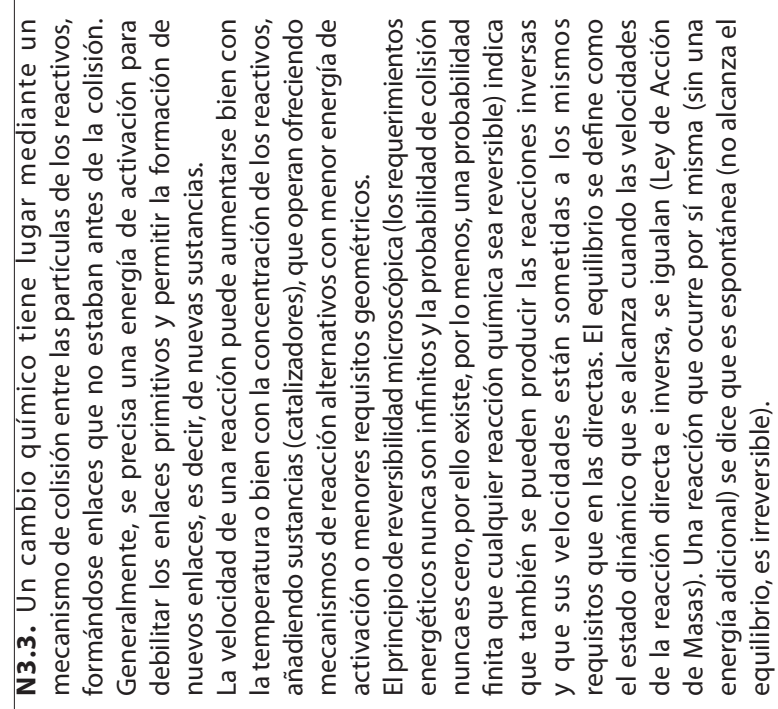

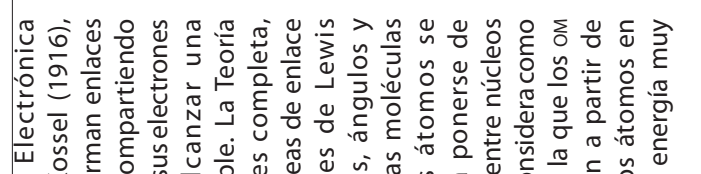

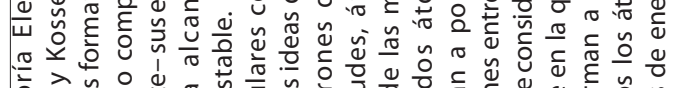

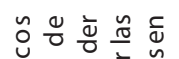
䍃

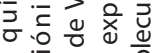

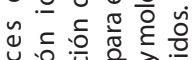

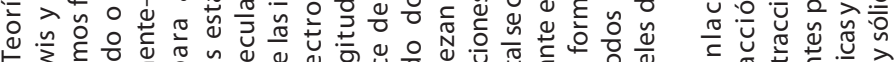
位 즈

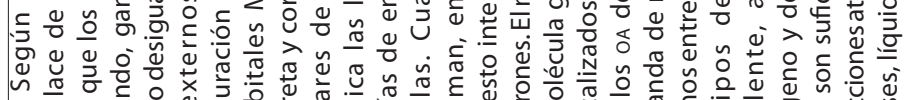

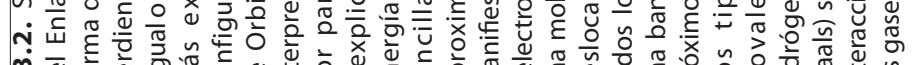

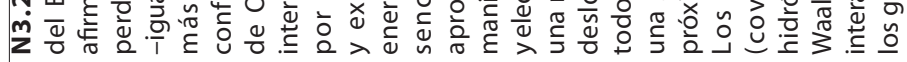

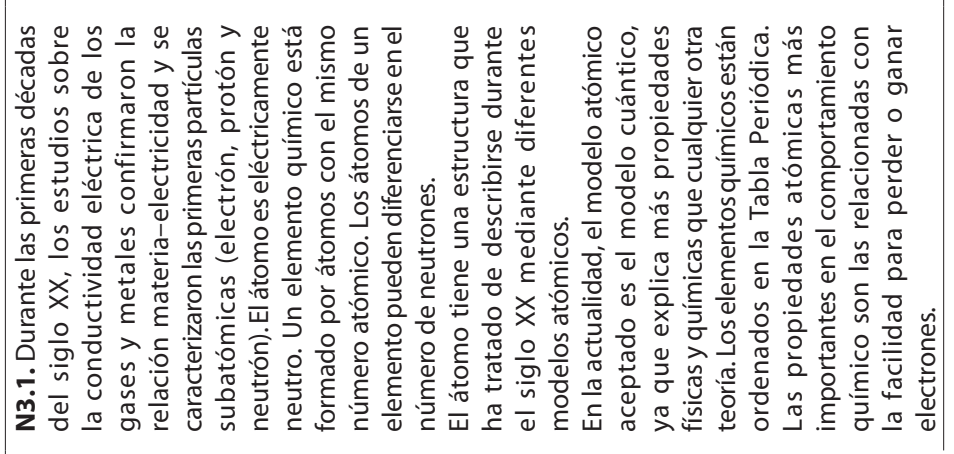

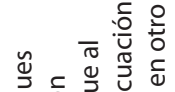

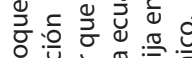

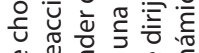
ชั

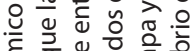

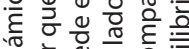

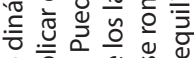

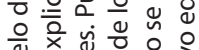
응 $x$

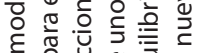

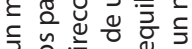
ㅎำ. 솔

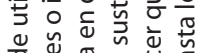

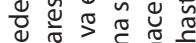
ว بิ

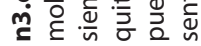

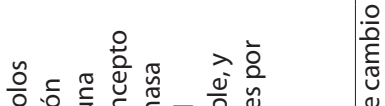

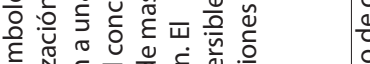

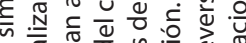

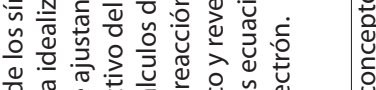

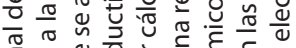

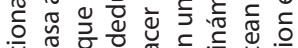

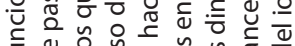

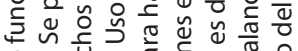
ㅇำ

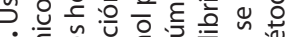
ㅇำ

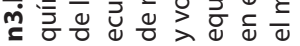

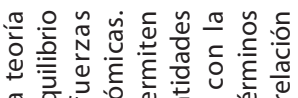

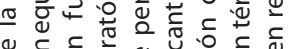

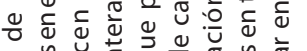

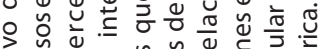

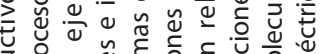

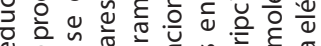

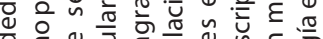

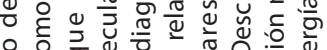

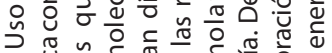

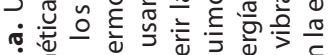

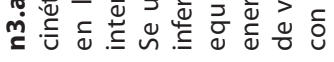

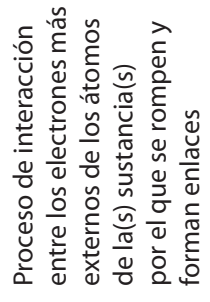




\section{Conclusiones}

Referidas al conocimiento didáctico del contenido, se ha mostrado que este concepto:

- Ha permitido contribuir a entender la didáctica de las disciplinas como un campo disciplinar dedicado a la enseñanza de los contenidos.

- Permite procedimientos de formación inicial y permanente del profesorado que puede ser interpretado desde distintas visiones, como las de transformación, transposición e integración.

- No ha tenido los desarrollos en la investigación educativa, si se compara con el conocimiento sobre la disciplina.

- Está formado por la integración de conocimiento-creencias del profesorado relacionado con el conocimiento disciplinar, el conocimiento histórico epistemológico articulado, el conocimiento psicopedagógico y contextual. En esta relación, por lo general, dependiendo del origen de la formación y la experiencia en el aula, pueden preponderar unos sobre otros o estar ausentes uno o varios de ellos de forma explícita.

En relación con las formas de identificar el CDC:

- Existen, en primer lugar, algunas propuestas reconocidas que consisten en articular el diseño, la acción y la reflexión del profesorado como medio de evaluación y desarrollo profesional docente, por ejemplo, aquellas que articulan los Repertorios de Contenido, ReCo, con los Repertorios de Experiencia Profesional Didáctica, ReEpd, los cuales se preocupan por las distintas variables que afectarían el aprendizaje constructivista de los contenidos; en segundo lugar, aquellas centradas en y preocupadas por la formación de competencias o desempeños del estudiante, EpC, para lo cual nos muestra gradientes de evolución de las ideas del estudiantado en cuatro niveles. Para ello, el profesorado diseña el currículo en torno a hilos conductores, tópicos generativos, metas de comprensión, desempeños de comprensión y evaluación continua, y, en tercer lugar, se presentan los Ámbitos de Investigación Profesional docente, AIP, mediante los cuales se muestran tres niveles de desarrollo profesional docente.

En relación con el diseño de tramas evolutivas del aprendizaje de los estudiantes en química general:

- Se proponen las tramas didácticas previas al diseño de unidades de enseñanza como un proceso de articulación de las tramas disciplinares e histórico-epistemológicas con tramas psicopedagógicas y contextuales con el fin de mejorar la relación enseñanza-aprendizaje en el estudiantado de química, mostrando un ejemplo concreto para el caso del concepto estructurante del cambio químico.

Para finalizar, podemos decir que hemos mostrado una panorámica general como marco conceptual de un campo disciplinar reciente, la cual puede contribuir al desarrollo profesional del ejercicio profesional docente en química con distintos indicadores explicitados desde los trabajos de varios grupos centrados en el desarrollo de distintos gradientes evolutivos de las ideas del estudiantado y profesorado, y que de igual manera nos permitirá elaborar fases de trabajo investigativo experimental. 


\section{Referencias bibliográficas}

Abell, S. y Lederman, N. (2007). Handbook of research on science education. Londres: Lawrence Erlbaum Associates.

Astolfi, J. P. (2001). Conceptos clave en la didáctica de las disciplinas. Sevilla, España: Diada Editora.

Bolívar, A. (2005). Conocimiento didáctico del contenido y didácticas específicas. Profesorado. Revista de currículum y formación del profesorado, 9(2).

Chevallard, I. (1991). La transposición didáctica. Del saber sabio al saber enseñado. Buenos Aires: Aique.

De Jong, O., Veal, W. y Van Driel, J. (2003). Exploring chemistry teachers knowledge base. En J. Gilbert et al (2003), Chemical education: towards research-based practice. Secaucus, Nueva Yersey: Kluwer Academic Publishers.

Furió, C., Gil, D., Pessoa de Carvalho, A. M. y Salcedo, L. (1992). La formación inicial del profesorado de educación secundaria: papel de las didácticas específicas. Investigación en la Escuela, 16, 7-21.

Gabel, D. (1998). The complexity of chemistry and implications for teaching. En K. G. Tobin y B. J. Fraser (s. f.), International handbook of science education (pp. 233-248). Gran Bretaña: Kluwer Academic Publisher.

García-Díaz, J. E. (1998). Hacia una teoría alternativa sobre los contenidos escolares. Sevilla: Diada Editora.

García-Pérez, F. y Porlán, R. (2000). El Proyecto Ires (Investigación y Renovación Escolar). Revista Bibliográfica de Geografía y Ciencias Sociales, 205. Extraído desde: http://www.ub.es/geocrit/ b3w-205.htm (04 / 04 / 2008)
García, A. y Garritz A. (2006). Desarrollo de una unidad didáctica: el estudio del enlace químico en el bachillerato. Enseñanza de las Ciencias, 24(1), 111-124.

Garritz, A. (2007). Análisis del conocimiento pedagógico del curso "Ciencia y Sociedad" a nivel universitario. Revista Eureka, 4(2), 226-246.

Garritz, A. y Trinidad-Velasco, R. (2004). El conocimiento pedagógico del contenido. Educación Química, 15(2), $1-6$.

Gess-Newsome, J. (1999). Pedagogical content knowledge: an introduction and orientation. En J. Gess-Newsome y N. Lederman (1999), Examining pedagogical content knowledge (pp. 3-17). Países Bajos: Kluwer Academic Publishers.

Gess-Newsome, J. y Lederman, N. (eds.) (1999). Examining pedagogical content knowledge. the construct and its implications for science education. Países Bajos: Kluwer Academic Publishers.

Gil, D. (1991). ¿Qué hemos de saber y saber hacer los profesores de ciencias? Enseñanza de las Ciencias, 9(1), 69-77.

Grossman, P., Wilson, S. y Shulman, L. (1989). Teachers of substance: subject matter konowledge for teaching. En M. Reynolds (s. f.), Knowledge base for the beginning teacher (pp. 23-36). Oxford: Pergamon Press.

Jensen, W. B. (1998). I. ¿Does Chemistry have a logical structure? Journal of Chemical Education. 6(75), 679-687.

Kincheloe, J. L. (2001). Hacia una revisión crítica del pensamiento docente. Barcelona, España: Octaedro. 
Loughran, J., Berry, A. y Mulhall, P. (2006). Understanding and developing science teachers' pedagogical content knowledge. Rotterdam: Sense Publishers.

Magnusson, S., Krajcik, J. y Borko, H. (1999). Nature, sources, and development of pedagogical content knowledge for science teaching. En J. Gess-Newsome y N. Lederman (eds.) (1999), Examining pedagogical content knowledge. The construct and its implications for science education (pp. 95-132). Países Bajos: Kluwer Academic Publishers.

Marcelo, C. (2005). La investigación sobe el conocimiento de los profesores y el proceso de aprender a enseñar. En A. Perafán y A. Adúriz-Bravo (comp.) (2005), Pensamiento y conocimiento de los profesores. Debate y perspectivas internacionales. Bogotá: Universidad Pedagógica Nacional.

Martín del Pozo, R. (1994). El conocimiento del cambio químico en la formación inicial del profesorado. Estudio de los conceptos disciplinares y didácticas de los estudiantes del Magisterio. Tesis Doctoral Inédita. Universidad de Sevilla España.

Martín del Pozo, R. y Rivero, A. (2001). Construyendo un conocimiento profesionalizado para enseñar ciencias en la educación secundaria: Los ámbitos de investigación profesional en la formación inicial del profesorado. $R e$ vista Interuniversitaria de Formación del Profesorado, 40, 63-79.

Mellado, V. (1996). Concepciones y prácticas de aula de profesores de ciencias, en formación inicial de primaria y secundaria. Enseñanza de las Ciencias, 14(3), 289-302.

Mora, W. y Parga, D. (2005). De las investigaciones en preconcepciones sobre mol y cantidad de sustancia, hacia el diseño curricular en química. Educación y Pedagogía, 43(XVII), 164-175.

Mora, W. y Parga, D. (2007). Tramas histórico-epistemológicas en la evolución de la teoría estructural en química orgánica. Tecné, Episteme y Didaxis, 21, 100-118.

Morine-Dershvier, G. y Kent, T. (1999). The complex nature and sources of teachers pedagogical knowledge. En J. Gess-Newsome y N. Lederman (eds.) (1999), Examining pedagogical content knowledge. The construct and its implications for science education (pp. 21-50). Países Bajos: Kluwer Academic Publishers.

Novak, J. D. (1977). Teoría y práctica de la educación. Madrid: Alianza Editorial.

Parga, D. y Martínez, L. (2007). Conocimiento didáctico del contenido $\mathrm{cu}$ rricular en química: una estrategia sustentada en el diseño de tramas conceptuales. Bogotá: Universidad Pedagógica Nacional. Colombia.

Parga, D., Mora, W. M. y Martínez, L. (2007). El conocimiento didáctico del contenido como programa de investigación: un contexto para la enseñanza de la química. En TED, número extra, 2007. Tercer congreso internacional sobre formación de profesores de ciencias, número extra, pág. Comunicación, 97. Bogotá.

Perrenoud, P. (2004). Desarrollar la práctica reflexiva en el oficio de enseñar: profesionalización y razón práctica. Barcelona, España: Graó.

Porlán, R. (2003). Principios para la formación del profesorado de secundaria. Revista Interuniversitaria de Formación del Profesorado. 17 (1), 23-35.

Porlán, R. y Rivero, A. (1998). El conocimiento de los profesores. Sevilla, España: Diada Editora. 
Reyes, F. y Garritz, A. (2006). Conocimiento pedagógico del concepto "reacción química” en profesores universitarios mexicanos. Revista Mexicana de Investigación Educativa, 11(31), 1175-1205.

Shayer, M. y Adey, P. (1984). La ciencia de enseñar ciencias. Desarrollo cognoscitivo y exigencias del currículo. Madrid: Narcea.

Shulman, L. S. (1986). 'Those who understand: knowledge growth in teaching. Educational Researcher, 15(2), 4-14.

Shulman, L. S. (1987). Knowledge and teaching: foundations of the reform. Harvard Educational Review, 57(1), 1-22.
Stone, M. (1999). La enseñanza para la comprensión. Vinculación entre la investigación y la práctica. Barcelona: Paidós.

Veal, W. (2004). Beliefs and knowledge in chemistry teacher development. International Journal of Science Education, 26(3), 329-351.

Wilson, S. y Shulman, L. (1987). “150 ways" of knowing: representations of knowledge in teaching. En J. Calderhead (s. f.), Exploring teacher thinking (pp. 104-124). Eastbourne, Inglaterra. 